\title{
0 gênero artigo científico e os manuais didáticos acadêmicos: um olhar sobre as propostas de ensino"
}

\author{
Gerenice Ribeiro de Oliveira Cortes
}

\begin{abstract}
Resumo: Este estudo se propõe a investigar o tratamento dado ao gênero artigo científico por manuais didáticos de apoio à escrita acadêmica, e examinar as concepções de língua, de escrita e de gênero subjacentes às propostas apresentadas. O corpus foi constituído dos seguintes manuais: 1) Redação científica: A prática de fichamentos, resumos, resenhas, de João Bosco Medeiros, publicado pela editora Atlas, 7. ed., 2005; 2) Como escrever artigos científicos: Sem arrodeio e sem medo da ABNT, de Ítalo de Souza Aquino, publicação da Editora Universitária UFPB, 2007; 3) Anatomia de um Artigo, de Antonio Souto, Editora Universitária UFPE, 2. ed. 2007. Este trabalho tem como embasamento teórico a concepção sociorretórica de gêneros textuais. Os resultados sugerem que o gênero artigo científico tem sido abordado nesses manuais, de forma homogênea, com maior ênfase nos aspectos formais, refletindo, assim, uma visão abstrata e descontextualizada do letramento acadêmico. Palavras-chave: Gênero Artigo Científico; Manuais Didáticos; Letramento Acadêmico.

Abstract. This paper aims to investigate the treatment given to the scientific article genre in teaching manuals for academic writing and to examine the concepts of language, writing and genre present in teaching manuals. The corpus includes the following manuals: 1) Redação cientifica: A prática de fichamentos, resumos, resenhas, by João Bosco Medeiros, published by Editora Atlas, seventh edition, 2005; 2) Como escrever artigos científicos: Sem arrodeio e sem medo da ABNT, by Ítalo de Souza Aquino, published by Editora Universitária UFPB, 2007; 3) Anatomia de um artigo, by Antonio Souto, Editora Universitária UFPE, second edition 2007. This study is based on the socio-rhetorical conception of textual genres. The results suggest that the scientific article genre has been approached in the same way in the manuals, with more emphasis on the formal aspects of the genre, which demonstrates an abstract and non contextual view of academic literacy.

Keywords. Research Article Genre; Teaching Manuals; Academic Literacy.
\end{abstract}

A comunidade discursiva da ciência estabelece convenções rígidas para a escrita dos diversos gêneros acadêmicos, fato que pode restringir ou negar o acesso de pessoas à comunidade científica caso não apresentem as habilidades necessárias para interagir academicamente por meio da escrita/leitura dos diferenciados gêneros. Destes, o artigo científico (AC) é considerado um dos principais veículos de socialização do conhecimento, além de exercer a função de inserir os novos pesquisadores nas respectivas comunidades científicas. Para tanto, o conhecimento amplo desse gênero torna-se fundamental,

\footnotetext{
Agradeço à professora doutora Beth Marcuschi, da Universidade Federal de Pernambuco, pelas valiosas contribuições dadas na construção da primeira versão deste estudo.

Gerenice Ribeiro de Oliveira Cortes, Prof ${ }^{a}$. Ms. Universidade Estadual do Sudoeste da Bahia - UESB E-mail: cortesgr@gmail.com
} 
pois, conforme argumenta Miller, "For the student, genres serve as keys to undestanding how to participate in the actions of a community." (MILLER, 1984, p. 67)

Um dos instrumentos de que dispõem os alunos - sobretudo os de graduação - para auxiliar na construção da escrita dos gêneros acadêmicos são os manuais didáticos. Estes diferem dos livros didáticos (LDs) convencionais, pois enquanto os LDs são adotados pelo professor para uso sistemático em sala de aula, como principal recurso didático - comumente no ensino fundamental e médio - e conta ainda com o exemplar do professor, o que aqui denominamos de manuais didáticos acadêmicos são instrumentos que se propõem a ajudar os alunos de ensino superior no apoio à escrita acadêmica e funcionam de forma mais autodidata. Percebemos, todavia, que o discurso didático está presente também nestes manuais.

Assim, partindo de uma concepção de língua enquanto atividade sociodiscursiva e de escrita como prática social, este estudo teve por objetivo refletir sobre o tratamento dado ao gênero artigo científico por esses manuais, investigando as concepções de língua, de escrita e de gênero subjacentes às propostas apresentadas e, dessa forma, ampliar o debate sobre a aquisição do letramento acadêmico.

O corpus foi constituído de três manuais, ${ }^{2}$ sendo que um trata da escrita acadêmica em geral (nosso interesse esteve centrado apenas na seção dedicada ao AC), e os outros dois se voltam especificamente para o gênero artigo científico. São eles: Redação científica: A prática de fichamentos, resumos, resenhas, de João Bosco Medeiros, publicado pela editora Atlas, 7. ed., 2005; Como escrever artigos cientificos: Sem arrodeio e sem medo da $A B N T$, de Ítalo de Souza Aquino, publicação da Editora Universitária UFPB, 2007; Anatomia de um artigo, de Antonio Souto, Editora Universitária UFPE, 2. ed. 2007.

Nosso foco de análise esteve voltado, sobretudo, para os seguintes aspectos: os objetivos estabelecidos no manual; a maneira como o gênero AC é abordado, tanto nos aspectos estruturais quanto nos aspectos funcionais; a concepção de língua, de escrita e de gênero subjacente às propostas apresentadas.

\footnotetext{
${ }^{1}$ "Para o aluno, gêneros funcionam como chaves para compreender a maneira de participar das ações de uma comunidade." - tradução nossa.

${ }^{2}$ Para a escolha dos livros, foi considerado o critério de melhor acesso e circulação no meio acadêmico. Quanto às publicações voltadas especificamente ao ensino do $\mathrm{AC}$, parece haver um número bastante limitado. 
O gênero artigo científico e os manuais didáticos acadêmicos...

A análise dos dados foi norteada com base nos pressupostos teóricos adotados.

\section{Os gêneros textuais}

Para conceituar gêneros, apoiamo-nos nos pressupostos de Bakhtin (2000), que defende gêneros discursivos como enunciados que se baseiam em formas-padrão e relativamente estáveis de estruturação de um todo.

É também fundamental o pensamento de Miller (1984, 1994), para quem gêneros são "ações retóricas tipificadas baseadas em situações recorrentes" (MILLER, 1984, p. 167). A noção de recorrência constitui um ponto-chave nos estudos de Miller sobre gêneros, porém essa recorrência não se restringe e não se centra aos/nos aspectos formais, mas na ação usada para a sua realização, pois para a autora gênero é "muito mais que uma entidade formal e isto o torna pragmático, retoricamente completo, um ponto de conexão entre intenção e efeito, um aspecto de ação social” (MILLER, 1984, p. 164). Para a autora, ao construirmos práticas discursivas, lidamos com propósitos de níveis diferenciados e aprendemos a adotar motivações sociais como um modo de satisfazer intenções particulares por meio de ação retórica.

Em consonância com essa visão, Marcuschi (2002) define a expressão gênero textual como "formas verbais de ação social relativamente estáveis realizadas em textos situados em comunidades de práticas sociais e em domínios discursivos específico" (MARCUSCHI, 2002, p. 25).

Bazerman, por seu turno, conceitua gêneros como "fatos sociais sobre os tipos de atos de fala que as pessoas podem realizar e sobre os modos como elas os realizam" (BAZERMAN, 2005, p. 31). Segundo o autor, os gêneros emergem nos processos sociais, em situações de interação. Para ele, a escrita, que se manifesta por meio dos gêneros, é imbuída de agência.

Desse modo, concordamos com Araújo (2000, p. 188) quando ela afirma que um ponto em comum na literatura sobre gêneros é a ênfase na sua ação social e no propósito compartilhado pelos membros da comunidade em que o gênero é praticado. Feitas essas considerações, falaremos a seguir, especificamente, do gênero artigo científico. 
2. O gênero artigo científico

Segundo Swales, o gênero artigo científico surge, de maneira embrionária, em 1665, contemporaneamente ao primeiro periódico científico - The Philosophical Transactions of the Royal Society -, a partir da troca de cartas entre pesquisadores enviadas ao periódico. Swales (1990, p. 93) conceitua o artigo de pesquisa como um texto escrito (embora possa conter elementos da linguagem não verbal) com o uso limitado de palavras que se reportam a algumas investigações por um ou mais autores. Para o autor, o artigo deverá estar relacionado com descobertas científicas em comparação com outras e poderá também examinar problemas teóricos e/ou de metodologia. Tais textos devem aparecer em jornais de pesquisa ou periódicos especializados.

No Brasil, as regras e convenções formais para a escrita do artigo científico (e dos demais gêneros acadêmicos) são reguladas pela Associação Brasileira de Normas Técnicas (ABNT). A NBR 6022 assim conceitua o AC: "Artigo científico é parte de uma publicação, com autoria declarada, que apresenta e discute ideias, métodos, técnicas, processos e resultados nas diversas áreas do conhecimento" (ABNT, 2003, p. 2). Essas normas, entretanto, nem sempre são seguidas de maneira rigorosa, pois cada revista ou periódico científico adota suas próprias normas editoriais, o que vai corroborar o pensamento de Kostelnick, (2003), quando afirma que são os membros dos grupos de uma comunidade que criam, definem, implementam, interpretam e sustentam as convenções, na interação. São, portanto, as comunidades científicas que definem normas, estilos e todo um conjunto de convenções linguístico-discursivas - que também tipificam os gêneros - e vão direcionar, principalmente, os aspectos formais das publicações.

Desse modo, há uma inter-relação entre gênero, convenções e comunidade discursiva que não deve ser ignorada. Não podemos, portanto, pensar o gênero artigo científico isoladamente, mas inserido nas diversas comunidades discursivas da ciência - espaço de produção e principal espaço de circulação desse gênero.

Swales (1990, p. 9) defende que os gêneros não são propriedade de indivíduos, mas pertencem às comunidades discursivas, as quais são definidas pelo autor como redes sociorretóricas que se formam a fim de atuar em torno de um conjunto de objetivos comuns, já que seus membros compartilham da 
O gênero artigo científico e os manuais didáticos acadêmicos...

familiaridade com gêneros específicos que são usados em causas comunicativas desse conjunto de objetivos.

\section{Gêneros textuais e letramento}

Na busca da compreensão dos processos sociais da leitura e da escrita, muitas discussões e debates têm sido travados na tentativa de se definir letramento, chegando-se ao consenso da existência de letramentos, ou diferentes enfoques do fenômeno, pois, segundo Soares (2002), não há propriamente uma diversidade de conceitos, mas diversidade de ênfases na caracterização do fenômeno. São comuns, portanto, encontrarmos as expressões letramento escolar, familiar, acadêmico, etc ou multiletramento, conforme pontua Dionisio (2006).

Constata-se que em todas as visões abordadas há um consenso geral: o letramento está sempre focalizado nas práticas sociais da leitura e da escrita. Em essência, é tornar evidente "a natureza social da escrita, uma vez que se refere ao conjunto das práticas sociais em cujo processo estão envolvidas atividades de leitura e de escrita" (LOPES, 2006, p. 44). Sendo assim, o letramento, que se manifesta nos gêneros textuais se caracteriza pela dinamicidade e heterogeneidade, inerentes às práticas sociais.

Quanto à questão do letramento acadêmico e ensino, no Brasil são poucas as discussões teóricas específicas sobre o tema. Podemos citar alguns trabalhos, como os de Motta-Roth (1999, 2000) e Araújo (2000). Motta-Roth ressalta as contribuições da análise de gênero para o ensino de redação acadêmica, pois "oferece uma abordagem socioconstrutivista do ensino de redação, uma vez que prevê a discussão de questões discursivas inerentes à interação, mediada pelo texto, entre pesquisadores (experientes e novatos)" (MOTTA-ROTH, 1999, p. 119). A autora também discorre sobre a importância de o aprendiz de gêneros acadêmicos desenvolver uma consciência metalinguística sobre o funcionamento discursivo desses gêneros, além de ampliar o domínio das convenções linguísticas da comunidade disciplinar (MOTTA-ROTH, 2000).

Não é comum encontrarmos reflexões sobre os manuais didáticos para fins acadêmicos, ao contrário do que acontece com os livros didáticos convencionais destinados aos ensinos médio e fundamental, que têm sido 
objeto de muitos estudos científicos em nível nacional. Acreditamos que esses manuais para fins acadêmicos não têm despertado a atenção dos pesquisadores em vista do seu caráter eminentemente autodidata, como já salientado. No entanto, tais livros estão no acervo das bibliotecas universitárias e, em alguns casos, constam na lista de indicações bibliográficas do programa de algumas disciplinas do ciclo básico da graduação, em algumas universidades.

\section{A abordagem do gênero artigo científico nos manuais didáticos acadêmicos}

Primeiramente apresentaremos uma visão geral dos três manuais que constituem o corpus deste estudo para, posteriormente, tecer as nossas considerações à luz do referencial teórico adotado.

Em sua "Introdução", a obra de Medeiros, denominada Redação científica: A prática de fichamentos, resumos, resenhas, apresenta o seguinte objetivo:

Redação científica: A prática de fichamentos, resumos, resenhas apresenta os mais variados instrumentos para a realização de trabalhos de pesquisa, objetivando levar ao conhecimento do leitor informações que possam favorecer-lhe no estudo, tornar sua leitura eficiente e eficaz, indicar-lhe caminhos para a pesquisa e a redação de trabalhos com embasamento científico, elaborados segundo técnicas de pesquisa bibliográfica. Este texto constrói-se a partir do tema básico da necessidade de leitura para superar dificuldades quanto à realização de trabalhos escritos. (MEDEIROS, 2005, p. 13)

O livro está subdivido em 13 capítulos, assim distribuídos: 1) "Como tornar o estudo e a aprendizagem mais eficazes", 2) "Pesquisa científica", 3) "Qualidade das fontes de pesquisa", 4) "Prática da leitura", 5) "Estratégias de leitura", 6) "Fichamento", 7) "Resumo", 8) "Resenha", 9) "Paráfrase e citações diretas", 10) "Como elaborar referências bibliográficas", 11) "Publicações científicas", 12) "Estrutura do texto dissertativo", e 13) "Apresentação gráfica da monografia”. 
O gênero artigo científico e os manuais didáticos acadêmicos...

No capítulo 11, "Publicações científicas", é dedicada uma seção de pouco mais de uma página ao artigo científico. Como se vê, o livro trata da leitura e da escrita de textos acadêmicos de um modo geral e portanto, não se propõe ao ensino específico do gênero artigo científico. Na breve abordagem dedicada ao gênero, Medeiros (2005, p. 243) apresenta o AC da seguinte forma:

O artigo científico trata de problemas científicos, embora de extensão relativamente pequena. Apresenta o resultado de estudos e pesquisas. E, em geral, é publicado em revistas, jornais ou outro periódico especializado. Os artigos cientificos permitem que as experiências sejam repetidas. (MEDEIROS, 2005, p. 243, grifo nosso)

O segundo manual tomado para essa análise é o de Aquino e seu título Como escrever artigos científicos: Sem arrodeio e sem medo da ABNT. O autor expõe logo no início o "Propósito" da obra, do qual extraímos o seguinte fragmento: "O propósito deste livro é ensinar aos jovens cientistas das universidades brasileiras e até mesmo aos alunos do ensino médio e técnico que já ensaiam a prática da ciência, como escrever artigos científicos sem arrodeio e sem medo da ABNT". (AQUINO, 2007, p. 8)

A obra está estruturada em 20 capítulos, assim distribuídos: 1) "Introdução", 2) "Ética na escrita"; 3) "A linguagem e a comunicação na pesquisa", 4) "Escrita técnica: Passo a passo", 5) "Como escrever: Título, autor(es), afiliação", 6) "Como escrever: Resumo, abstract/resumen", 7) "Como escrever: Palavras-chave", 8) "Como escrever: Introdução", 9) "Como escrever: Objetivo", 10) "Como escrever: Materiais e método", 11) "Como escrever: Resultados", 12) "Como escrever: Discussão", 13) "Como escrever: Conclusão", 14) "Como escrever: Agradecimentos", 15) "Como escrever: Bibliografia", 16) "Como escrever: Projetos", 17) "Como escrever: TCC, monografias, dissertação e tese", 18) "Os erros mais freqüentes", 19) "Estratégias adicionais", 20) "Porque publicar".

O terceiro manual examinado foi o de Antonio Souto, Anatomia de um artigo científico. A obra está estruturada da seguinte forma: "Prefácio", "Prefácio da 2." edição", 1) "Primeiras noções", 2) "A introdução", 3) "O material e métodos", 4) "Os resultados", 5) "A discussão" 6) "O todo e importantes detalhes", "Bibliografia". 
No prefácio à segunda edição, o autor mostra o seu objetivo com a publicação:

Há cerca de seis anos me senti compelido a escrever um livro que abordasse a elaboração de um artigo experimental. A busca por uma produção neste formato já era de tal ordem desejada que exigia um grande esforço, principalmente dos alunos. Julguei importante, então, a elaboração de um livro que facilitasse tal atividade. O resultado foi algo com as características de um manual de consulta, facilmente compreendido, por possuir muitos exemplos de rápido entendimento. (SOUTO, 2007, p. 10)

No capítulo 1 é apresentada a seguinte definição para artigo científico: "um escrito, no qual aborda-se um problema, formula-se um hipótese ou objetivo, que é testado empiricamente, obtendo-se respostas que devem ser discutidas" (SOUTO, 2007, p. 11).

Ainda no primeiro capítulo, o autor justifica o fato de a sua obra limitar-se ao artigo científico com experimentação:

Talvez, envolver tão somente artigos de experimentação possa parecer um tremendo limite, por não cobrir uma série de outras formas, inclusive aquela pertinente às ciências formais (como a lógica e a matemática) ou que se baseiam em teorias, expressas matematicamente. Todavia, justifico esse caminho por ser o artigo com experimentação o mais comum dentro das ciências (biológicas, físicas, químicas etc.), e aquele que o aluno abordará com uma maior frequência em sua formação acadêmica. (SOUTO, 2007, p. 12)

Já fica explícito, portanto, desde o início, que a estrutura do artigo apresentada pelo autor é a IMRD (introdução, materiais e métodos, resultados e discussão), estrutura predominante, principalmente nos artigos das chamadas ciências da natureza. Para cada uma das seções do artigo já apresentadas no sumário, Souto, além de explicar o objetivo daquela seção, ilustra com diversos exemplos de textos de autores da área das ciências naturais, conforme se vê nos trechos reproduzidos a seguir: 
O gênero artigo científico e os manuais didáticos acadêmicos...

Capítulo I - A introdução - [...] em um artigo sobre o uso de um jogo de ferramentas por macaco-pregos, Westergaard e Suomi (1993) iniciam a introdução da seguinte forma: [...] Vejamos agora o trabalho de Bugnyar e Huber (1997) intitulado "Empurrar ou puxar: um estudo experimental sobre a imitação em saguis comuns", o qual tem um começo nos moldes dos dois trabalhos anteriores [...]. (SOUTO, 2007, p. 20-21)

Nos três manuais, encontramos algumas características bastante similares. A concepção de linguagem, de língua escrita e de gêneros subjacente às obras vai se tornando evidente à medida que adentramos na leitura dos textos. Assim, passaremos a mostrar como essas concepções vão sendo entremeadas pelas abordagens construídas nos manuais.

\section{Visão homogênea de língua escrita e de gêneros textuais}

A primeira característica que se apresenta de maneira bastante explícita, comum às três obras, é a visão homogênea de língua e de gênero. pronuncia:

Medeiros, ao apresentar os aspectos estruturais do artigo, assim se

Estruturalmente, são compostos de: título do trabalho, autor, credenciais do autor, local das atividades; sinopse (resumo em português e em uma língua estrangeira, de preferência, em inglês); corpo do artigo (introdução, desenvolvimento e conclusão); parte referencial (referências bibliográficas, como notas de rodapé ou final de capítulo, bibliografia, que é a lista dos livros consultados ou relativos ao assunto, apêndice, anexos, agradecimentos, data). (MEDEIROS, 2005, p. 244)

Apesar de, mais adiante, o autor afirmar que a redação do artigo leva em conta o público a que se destina, ele apresenta uma única estrutura para a composição dos artigos, não levando em conta a heterogeneidade da escrita e dos gêneros textuais.

A estrutura apresentada para o artigo científico no manual de Aquino é a chamada IMRD. Essa estrutura, que já se evidencia a partir do sumário, é 
apresentada no capítulo 6, que trata de como escrever o resumo, e estende-se ao corpo do livro.

No capítulo 5, que trata da escrita dos títulos do artigo, o autor afirma que o título "1) [...] deve ser simples, completo, geralmente curto (10 a 20 palavras*) e com o(s) nome(s) científico(s) do ser vivo sem erro(s) [quando aplicável].” (AQUINO, 2007, p. 37, grifo nosso).

Ora, mesmo com a observação "quando aplicável” no final, o autor, de certa forma, já direciona a orientação para a escrita de artigos em uma área bastante específica. Nas orientações para a escrita do resumo (capítulo 6), temos o seguinte: "(2) O Resumo deve conter: Introdução (uma a duas frases), objetivo(s), materiais e método, resultados, discussão e conclusão(ões). O Resumo deve ser escrito de forma impessoal (200-300 palavras*), sem parágrafos." (AQUINO, 2007, p.41).

O modo como se estrutura a obra e se dá a distribuição dos capítulos reflete a visão homogênea do gênero AC. Isso fica mais evidente a partir do capítulo 5, que se inicia com o uso da expressão "como escrever", a qual se repete até o capítulo 17 . Trata-se de uma estrutura textual bastante similar à do gênero receita culinária. O que subjaz aqui é a ideia de receita, "como fazer", mas essa concepção de escrita e de gênero enquanto receita não leva em conta os aspectos heterogêneos, os processos sociais da escrita e das atividades acadêmicas.

As ações sociais da escrita não são consideradas nessa visão prescritiva, formalista e homogênea de gênero. Ao exemplificar as seções do artigo, Aquino apresenta fragmentos de textos de apenas uma área científica: as ciências naturais. A título de ilustração, encontramos no capítulo 6 um exemplo de resumo com o seguinte título: "Efeito da Combustão de Cigarro Comercial no Aprendizado de Abelhas Operárias (appis mellifera L.)" (Aquino 2007, p. 46). Essa restrição a uma área específica do conhecimento se evidencia em todos os capítulos do livro, como mostram os exemplos abaixo:

Cap. 9. Como escrever: Objetivo - Exemplo 1: Objetivo com hipótese presente: [...] Um estudo conduzido por Aquino et al. (1993) sugere que a cera de abelha pode ser uma alternativa plausível na criação de parasitóides [...] (AQUINO, 2007, p. 53) 
O gênero artigo científico e os manuais didáticos acadêmicos...

(4) Cap. 10 - Como escrever: Materiais e método-Materiais e método é a parte mais detalhada do projeto/artigo (600-900 palavras*). Aqui, você tem que detalhar o material utilizado, o lugar onde serálfoi conduzido o experimento e o método de condução do trabalho. Mais uma vez [...] não seja subjetivo nem extremamente detalhista. [...] Em M \& M utiliza-se no passado (utilizou-se, foi conduzido...) para artigos a serem publicados [...] Em geral, o local do experimento vem em primeiro lugar. (AQUINO, 2007, p. 57, grifo nosso).

Como se pode verificar, no capítulo sobre materiais e métodos já se faz uma restrição a uma área específica do conhecimento científico que trabalha com experimentos. Após essas instruções, o autor apresenta um fragmento de texto da seção $M \& M$, da qual reproduzimos o seguinte:

O experimento foi conduzido no apiário do Centro de Ciências Agrárias (CCA) da Universidade Federal da Paraíba (UFPB). Utilizaram-se 400 (quatrocentas) abelhas operárias (Apis mellifera L.) [...] As fotos das abelhas foram tiradas com uma câmara digital modelo MVC-FD75, Sony [...]. (AQUINO, 2007, p. 57-58)

Essa ideia de "prescrição" para a escrita do artigo científico perpassa todo o manual, sempre direcionado para uma área específica do conhecimento. Vejamos a evidência dessa afirmação: "Cap. 11. Como escrever: Resultados: Nos Resultados você deve ilustrar com Figura(s) ou Tabela(s), a(s) qual(is) deve(m) estar intercaladas(s) com parágrafos explicativos (400-500 palavras*)". (AQUINO, 2007, p. 61)

Ora, sabemos que nem todos os estudos necessitam de experimentos, tabelas ou figuras para a comprovação de suas teses. A ideia que subjaz aos textos é a de que só são considerados científicos os processos que apresentarem essas características e percorrerem esses caminhos. As peculiaridades sociais e culturais das demais comunidades científicas não são mencionadas nem consideradas.

O manual de Aquino apresenta também um capítulo que se propõe a ensinar "Como escrever: Agradecimentos". Aqui ele apresenta as seguintes considerações: "Agradecimentos é um pequeno espaço dentro de um artigo 
científico reservado para expressar gratidão por relevantes colaborações, principalmente financeira [...]" (AQUINO, 2007, p. 71)

O autor menciona essa seção do artigo como sendo válido para a escrita desse gênero em todas as áreas científicas. Entretanto, essas normas e convenções apresentem variações de comunidade para comunidade, e às vezes esse fator tem sido ignorado, mas os gêneros não são homogêneos, como a linguagem também não o é. A heterogeneidade é um traço inerente não só ao discurso acadêmico e aos gêneros, como também à língua.

Algumas pesquisas têm mostrado que há diversidade nos padrões e convenções dos gêneros acadêmicos no interior das diversas disciplinas, em vista das características peculiares das comunidades discursivas (HOLMES, 1997; HYLAND, 1999, 2000; SOLER, 2007; OZTURK 2007). O estudo de Holmes, por exemplo, evidenciou que os artigos de ciências sociais apresentam padrões significativamente diferentes daqueles observados nos artigos de ciências naturais. Segundo o autor, este dado pode ser de grande valor para o ensino da escrita científica, pois amplia o entendimento da natureza dos textos acadêmicos. Ele argumenta que "os artigos de ciências naturais e de ciências sociais podem, portanto, ser olhados como o resultado de uma negociação de confiança entre as "partes" de um mesmo gênero" (HOLMES, 1997, p. 331) Para o autor, eles, entretanto, não são idênticos: os artigos de ciência política e de sociologia, por exemplo, assemelham-se suficientemente e, ao mesmo tempo, são suficientemente distintos dos artigos de ciências naturais.

Nessa perspectiva, Rezende e Hemais também preconizam que

O gênero artigo científico é comum a várias áreas. Contudo, cada área o elabora de uma maneira peculiar, frequentemente havendo diferenças léxico-gramaticais, semântico-pragmáticas e de organização retórica entre áreas distintas. Essas diferenças se explicam pelo fato de que em cada comunidade existem peculiaridades que determinam como a comunidade vai construir o conhecimento disciplinar. (REZENDE; HEMAIS, 2004, p. 132)

Não se pode admitir, portanto, uma visão homogênea do discurso acadêmico: 
O gênero artigo científico e os manuais didáticos acadêmicos...

[...] há diferenças de várias ordens no interior do discurso acadêmico, começando pelas diferenças entre disciplinas. Não se escreve da mesma forma em literatura ou em linguística: há modos de argumentar, de sustentar um argumento, ou de produzir conhecimentos diferenciados na academia, em diferentes áreas disciplinares. Assim, a noção de discurso disciplinar implica uma determinada visão teórica das disciplinas: as diferenças entre disciplinas são muito mais do que diferenças epistemológicas (ou diferenças de conteúdo): as diferenças são vistas cada uma como uma cultura, com regras próprias de interação social e com práticas discursivas específicas. (BALLOCO, 2004, p. 629)

Visualizar essa variedade no discurso acadêmico é, portanto, compreender que "embora os textos apresentem uma ordem mais ou menos típica, esta não deve ser a única a ser usada" (ARAUJO, 2000, p. 190).

A pesquisa de Cortes (2009) também aponta padrões diferenciados na estrutura retórica dos artigos científicos de História e Sociologia.

Assim, faz-se necessário entender "que uma das principais preocupações de gênero é explicitar o conhecimento sobre como um texto é constituído e como ele varia de acordo com o propósito, tópico, audiência-alvo e canal de comunicação" (ARAUJO, 2000, p. 194). É reconhecer que as regularidades formais e de conteúdo - que visualizamos nos gêneros - na verdade são reflexos de ações sociais que se dão em situações retóricas recorrentes (MILLER, 1984). E essas situações recorrentes é que vão, segundo Miller, determinar a utilização deste ou daquele gênero, conforme a demanda social de cada contexto e de acordo com as circunstâncias.

\section{Concepção monológica de linguagem}

O monologismo se revela nos manuais analisados por meio de uma preocupação exacerbada em salientar a objetividade na escrita acadêmica. Trata-se, segundo Coracini (1992), de uma visão da suposta imparcialidade da ciência que é transposta para os textos de relatos científicos, por meio de estratégias formais, na busca pela ilusão da objetividade.

O manual de Medeiros ressalta que "o estilo, como em qualquer trabalho científico, deve ser claro, conciso e objetivo" (MEDEIROS, 2005, p. 
244). Quanto à linguagem, deve ser, segundo ele "gramaticalmente correta, precisa, coerente, simples e, preferencialmente, em terceira pessoa" (MEDEIROS, 2005, p. 244).

Essa característica é visível também na obra de Aquino. No capítulo 3, "A linguagem e a comunicação na pesquisa", o autor faz as seguintes afirmações:

A linguagem e a comunicação na pesquisa científica são objetivas. Não se pode colocar termos subjetivos [...] Em qualquer que seja a modalidade da apresentação (produto final da pesquisa), a linguagem é a mesma: técnica; a comunicação é a mesma: objetiva. (AQUINO, 2007, p. 29, grifos do autor).

Percebemos que o discurso evidenciado nos três manuais é perpassado pelo discurso da suposta objetividade e neutralidade defendidas pelo racionalismo científico, que tenta apagar a subjetividade do pesquisador. Todavia, declara Bakhtin, a palavra não conhece um objeto como algo pronto ou dado, e "o simples fato de que eu comecei a falar sobre ele já significa que eu assumi uma certa atitude sobre ele - não uma atitude indiferente, mas uma atitude efetiva e interessada" (BAKHTIN, 1993, p. 33). Trata-se, segundo ele, da nossa entonação e atitude valorativa em direção ao objeto. E assim como não podemos apagar a nossa atitude sobre o objeto científico, não há também como negar o caráter essencialmente dialógico da linguagem humana.

Tal preconceito leva o discurso científico, segundo Leibruder (2000), a apresentar os fatos como se adquirissem vida e falando por si mesmos, assumindo, assim, um caráter de neutralidade e de inquestionabilidade. Nesse discurso, segundo a autora, "todo e qualquer resultado obtido será, a priori, uma verdade incontestável" (LEIBRUDER, 2000, p. 231). O discurso científico tenta apresentar-se ao leitor não como uma interpretação e sim como a própria realidade. Segundo Bakhtin (2000), o chamado estilo "neutro" ou objetivo, essencialmente concentrado no seu objeto, parece ignorar o outro, e se constrói à custa da recusa dos recursos de expressividade.

Hyland (1999) argumenta que as convenções de impessoalidade nos artigos têm a função de reforçar essa ideologia, por retratar a legitimação do conhecimento da ciência dura como construída sobre critérios socialmente invariáveis. Neste sentido, Motta-Roth (2005) também questiona o estatuto e as visões monolíticas do texto científico. 
O gênero artigo científico e os manuais didáticos acadêmicos...

Nos manuais analisados, há, portanto, uma preocupação bastante acentuada com a objetividade na linguagem, mas não podemos nos esquecer de que toda atividade linguística pressupõe a interação e, portanto, a presença do outro no discurso. Os autores direcionam suas instruções da escrita do artigo científico em ciências naturais como sendo válidas para todas as áreas científicas, embora os títulos das obras não sinalizem essa restrição.

\section{Visão descontextualizada de gênero}

Em nome do status de cientificidade, os manuais analisados apresentam a escrita do gênero AC como uma atividade monológica, homogênea e desvinculada do contexto das práticas sociais. Todavia, concordamos com Malufe quando ele afirma que a publicação de um escrito científico não pode se reduzir à comunicação de um conteúdo, mas "é também uma forma de instaurar e operar um conjunto de relações sociais" (MALUFE, 1992, p. 20).

Os três manuais considerados neste estudo apresentam as orientações para a escrita da seção de materiais e métodos de maneira prescritiva, como se a atividade científica - e o seu relato - acontecessem nos mesmos contextos, com os mesmos sujeitos, nas mesmas situações e circunstâncias, com os mesmos propósitos, para respostas às mesmas demandas e se dirigissem à mesma audiência-alvo. Entretanto, como afirma Motta-Roth (2000), texto e contexto social se imbricam.

Essa visão descontextualizada de gênero pode ser vista, por exemplo, na seguinte afirmação de Medeiros: "Os artigos científicos permitem que as experiências sejam repetidas.” (MEDEIROS, 2005, p. 243) Já em Aquino, temos a seguinte observação sobre a explicitação do método no artigo: "O método utilizado na condução de sua pesquisa deve ser detalhado (não em excesso), levando em conta que pessoas da área entendem e podem, se desejar, repetir o seu experimento" (AQUINO, 2007, p. 59, grifo nosso). Por sua vez, Souto, na abertura do seu terceiro capítulo, ao tratar de material e métodos no $\mathrm{AC}$, refere-se a essa seção explicitamente como uma receita:

Já imaginou o que seria dos pratos culinários se não existissem receitas? Pois bem, se não fossem as "receitas" (leia-se o "material e métodos") dos artigos não teríamos ciência do ponto de vista mais rigoroso! Isso 
porque não basta apenas que haja a experimentação, é preciso, e fundamental, que haja a possibilidade de repetição. (SOUTO, 2007, p. 41)

Isto diz respeito, segundo Motta-Roth, "ao mito da verossimilhança na metodologia científica". Segundo ela, "algumas discussões recentes têm apontado as diferenças existentes entre o formato final do texto publicado e o que de fato acontece durante a pesquisa empírica" (MOTTA-ROTH, 2005, p. 67). A autora reporta-se aos estudos de Swales (1990) e Gilbert e Mulkay (1984), segundo os quais a ação social, que dá forma à pesquisa, tem sido neglicenciada no discurso científico modernista, que respalda o mito da verossimilhança. Citando Atkinson, a autora faz a seguinte afirmação:

Os artigos davam a impressão de que os métodos eram totalmente rotineiros e facilmente repetíveis. Todavia, durante a entrevista, esses pesquisadores sugeriram que aderir fielmente à metodologia de um autor para obter os mesmos resultados é praticamente impossível, mesmo contando com descrições detalhadas. (MOTTA-ROTH, 2005, p. 67).

Concordamos com Motta-Roth que a textualização da prática científica é consequência da nossa própria visão de ciência, e portanto os manuais analisados revelam essa concepção tão arraigada historicamente. Hyland (1999) argumenta que, nessa visão, o julgamento humano mediando a ligação na interpretação dos dados é subestimado, as descrições dos fenômenos mostra-os como representando uma realidade independente do observador, $\mathrm{e}$ os métodos empíricos são reificados nas convenções da narrativa científica. Segundo o autor, os cientistas agem como se eles vissem a si mesmos descobrindo verdades, não as construindo. Sua pesquisa mostrou que os artigos das ciências duras ainda sugerem que o conhecimento é realizado pela aplicação correta de procedimentos prescritos e que a natureza se revela diretamente, em si mesma, por meio do método científico (HYLAND, 1999, p. 355). Essa parece ser, portanto, a visão de ciência subjacente aos manuais didáticos ora examinados.

Outro aspecto que nos chamou a atenção diz respeito às orientações apresentadas nos manuais para a prática das citações nos artigos, posto que são orientações que se restringem aos aspectos técnicos e éticos. Todavia, entendemos que seria necessário destacar, ainda que de forma sucinta, os 
O gênero artigo científico e os manuais didáticos acadêmicos...

aspectos dialógicos e as funções retóricas das citações (ALLEN; QIN; LANCASTER, 1994).

Segundo Kelly e Bazerman (2003, p. 29), a atividade epistêmica de pesquisadores é formada por interesses retóricos: quem será convencido de que, como outros irão responder ao novo trabalho, qual a organização da atividade comunicativa, e quais as metas de cooperação da comunidade. Nos três manuais analisados, essa preocupação não é evidenciada, o que pode demonstrar uma visão bastante técnica das citações e do gênero ora analisado.

\section{Considerações finais}

De acordo com os estudos de Miller (1984, 1994), o gênero, visto como ação social, envolve a situação retórica, além dos elementos do contexto, o motivo do falante e o efeito pretendido, isto é, o propósito comunicativo estabelecido pelo falante a partir de necessidades situacionais. Entretanto, nos manuais de Medeiros, Aquino e Souto o ensino da escrita do AC evidencia uma preocupação centrada quase unicamente nos aspectos estruturais do texto, a partir de critérios e convenções rígidas de uma única área científica.

A análise dos dados aponta para o fato de que, embora algumas pesquisas já tenham demonstrado a existência de sensíveis variações epistemológicas e discursivas entre as disciplinas, o gênero artigo científico é abordado nesses manuais de maneira bastante estrutural, prescritiva e homogênea, revelando uma concepção de linguagem monológica, fora da realidade das interações sociais.

As convenções textuais para a escrita do AC, nos manuais examinados, sugerem a existência de homogeneidade entre as comunidades científicas. Entretanto, essas convenções linguístico-discursivas, de acordo os estudiosos, são construídas nos processos sociais, culturais, em situações de interações entre os membros das comunidades. Conforme postula Kostelnick (2003), as convenções revelam as ações dos usuários, tanto aqueles que as empregam conscientemente quanto os leitores que as interpretam, juntamente constroem o sentido dos códigos de uso, os quais são criados, difundidos e sustentados por grupos sociais.

Os fatores sociais estão, portanto, imbricados na construção e no uso dos gêneros, que não podem ser vistos fora de seu contexto amplo. Assim, a abordagem do gênero $\mathrm{AC}$ nos manuais sugere uma concepção de gênero 
que se assenta mais em formas e classificações, e não leva em conta o propósito comunicativo e o fato de que os gêneros mudam, desenvolvem-se e entram em desuso. $\mathrm{O}$ conjunto de gêneros de uma sociedade é indeterminado e se reveste de complexidade e diversidade inerentes às práticas discursivas (MILLER,1984).

Em vista do que foi apresentado, faz-se necessário assumirmos uma visão crítica em relação aos manuais de apoio à escrita acadêmica, a fim de não perpetuar visões monolíticas. Afinal, conforme assinala Miller (1984), quando aprendemos um gênero não aprendemos um conjunto de formas, mas aprendemos a realizar as mais variadas práticas discursivas, no intuito de realizar as nossas metas.

\section{Referências}

AQUINO, Italo S. Como escrever artigos científicos: sem arrodeio e sem medo da ABNT. João Pessoa: Editora Universitária UFPB, 2007.

ASSOCIAÇÃO BRASILEIRADE NORMAS TÉCNICAS. NBR 6022: informação e documentação - artigo em publicação periódica científica impressa - apresentação. Rio de Janeiro: ABNT, 2003.

ALLEN, B; QIN, J; LANCASTER, F. W. Persuasive Communities: a longitudinal analysis of references in the philosofical transactions of the Royal Society -16651990. Social Studies of Science, v. 24, 1994, p. 279-310.

ARAÚJO, A. D. Análise de gênero: Uma abordagem alternativa para o ensino da redação acadêmica. In: MAILCE, B. M.; FORTKAMP; L.; TOMITCH, Maria B. (Orgs.). Aspectos da lingǘstica aplicada: estudos em homenagem ao professor Hilário Inácio Bohn. Florianópolis: Insular, 2000.

BAKHTIN, M. (VOLOSHINOV, V. N.). Marxismo e filosofia da linguagem. São Paulo: Hucitec, 1992.

. Para uma filosofia do ato. Inédito, 1993.

. Os gêneros do discurso. In: BAKHTIN, M. Estética da criação verbal. São Paulo: Martins Fontes, 2000, p. 277-326.

BALOCCO, A. E. Gênero e identidade: um estudo de caso. Disponível em < $<$ http:// www3.unisul.br/paginas/ensino/pos/linguagem/cd/Port/19.pdf>. 2004. Acesso em: 13 set. 2007.

BAZERMAN, C. Gêneros textuais, tipificação e interação. São Paulo: Cortez, 
2005.

CORTES, G. R. O. Práticas sociorretóricas do gênero artigo científico de história e sociologia: variação, ethos e identidade disciplinar. Dissertação (Mestrado). Universidade Federal de Pernambuco. Recife, 2009.

DIONISIO, A. P. Gêneros multimodais e multiletramento. In: KARWOSKI, A. et al. (Orgs.). Gêneros textuais: reflexões e ensino. São Paulo: Lucerna, 2006.

HOLMES, R. Genre analysis, and the social sciences: an investigation of the structure of research article discussion sections in three disciplines. English for Specific Purposes, v.16, n. 4, 1997, p. 321-37.

HYLAND, K. Academic attribuition: Citation and the construction of disciplinary knowledge. Applied Linguistics, v. 20. n. 3, p. 341-67, 1999.

KELLY, G. J.; BAZERMAN, C. How students argue scientific claims: a rhetoric-semantic analysis. Applied Linguistics, v. 24, n. 1, 2003, p. 28-55.

KOSTELNICK, C. Shaping information: the rhetoric of visual conventions. Southern Illinois University, 2003.

LEIBRUDER, A. P. O discurso de divulgação científica. In: BRANDÃO, H. N. Gêneros do discurso na escola. São Paulo: Cortez, 2000.

LOPES, Iveuta A. Cenas de letramentos sociais. Recife: Programa de Pós-Graduação em Letras da UFPE, 2006.

MARCUSCHI, L. A. Gêneros textuais: configuração, dinamicidade e circulação. In: KARWOSKI, A. M.; GAYDECZKA, B.; BRITO, K. S. (Orgs.). Gêneros textuais: reflexões e ensino. São Paulo: Lucerna, 2006.

Gêneros textuais: definição e funcionalidade. In: DIONÍSIO, A. P.; MACHADO, A. R.; BEZERRA, M. A. Gêneros textuais \& ensino. Rio de Janeiro: Lucerna, 2002.

MALUFE, J. R. A retórica da ciência: uma leitura de Goffman. São Paulo: Educ, 1992.

MEDEIROS, J. B. 2005. Redação científica: a prática de fichamentos, resumos, resenhas. Sao Paulo: Atlas, 2005.

MILLER, Carolyn R. Rhetorical comunity: the cultural basis of genre... In: FREEDMAN, A.; MEDWAY, P. Genre and new rhetoric. Londres: Taylor \& Francis, 1994, p. $67-78$. 1984.

. Genre as social action. Quarterly Journal of Speech, v. 70, p. 151-67, 
MOTTA-ROTH, D. Abordagens investigativas no estudo de práticas discursivas: uma questão de metodologia ou de bom senso? In: FREIRE, M. M; ABRAHÃO, M. H. V; BARCELOS, A. M. F. (Orgs.). Linguística aplicada e contemporaneidade. Campinas/São Paulo: Pontes/Alab, 2005.

Gêneros discursivos no ensino de línguas para fins acadêmicos. In: FORTKAMP, Mailce B. M.; TOMITCH, L. M. B. (Orgs.). Aspectos da linguística aplicada: Estudos em homenagem ao professor Hilário Inácio Bohn. Florianópolis: Insular, 2000.

A importância do conceito de gêneros discursivos no ensino de redação acadêmica. Intercâmbio, v. 8, p. 119-28,1999.

OZTURK, I. The textual organisation of research article introductions in applied linguistics: Variability within a single discipline. English for Specific Purposes, v. 26, p. 25-38, 2007.

REZENDE, P.; HEMAIS, B. Análise comparativa de artigos científicos da área de saúde. The Especialist, v. 25, n. 2, p. 131-52, 2004.

SOARES, M. Letramento: um tema em três gêneros. Belo Horizonte: Autêntica, 1998.

SOUTO, Antonio. Anatomia de um artigo. Recife: Editora Universitária UFPE, 2007.

SWALES, J. Genre analysis: english in academic and research settings. Cambridge: Cambridge University Press, 1990.

Recebido para publicação em 23 de julho de 2009. Aceito para publicação em 04 de março de 2010. 